\title{
Climate change and ecosystem composition across large landscapes
}

\author{
Michael D. Jennings • Grant M. Harris
}

Received: 13 April 2016/Accepted: 5 August 2016/Published online: 22 August 2016

(C) The Author(s) 2016. This article is published with open access at Springerlink.com

\begin{abstract}
Context Climate change alters the vegetation composition and functioning of ecosystems. Measuring the magnitude, direction, and rate of changes in vegetation composition induced by climate remains a serious and unmet challenge. Such information is required for a predictive capability of how individual ecosystem will respond to future climates.

Objectives Our objectives were to identify the relationships between 20 climate variables and 39 ecosystems across the southwestern USA. We sought to understand the magnitude of relationships between variation in vegetation composition and bioclimatic variables as well as the amount of ecosystem area expected to be affected by future climate changes.
\end{abstract}

Electronic supplementary material The online version of this article (doi:10.1007/s10980-016-0435-1) contains supplementary material, which is available to authorized users.

M. D. Jennings $(\bowtie)$

Department of Geography, University of Idaho, McClure

Hall 203, Moscow, ID 83844-3021, USA

e-mail: jennings@uidaho.eu

G. M. Harris

Division of Biological Sciences, US Fish and Wildlife

Service Southwestern Region,

PO Box 1306, Albuquerque, NM 87103-1306, USA

Present Address:

M. D. Jennings

Forest Health Center, US Forest Service, 1401 Gekeler Ln.,

La Grande, OR 97850, USA
Methods Bioclimatic variables best explaining the plant species composition of each ecosystem were identified. The strength of relationships between beta turnover and bioclimate gradients was calculated, the spatial concordance of ecosystem and bioclimate configurations was shown, and the area of suitable climate remaining within the boundaries of contemporary ecosystems under future climate projections was measured.

Results Across the southwestern USA, four climate variables account for most of the climate related variation in vegetation composition. Twelve ecosystems are highly sensitive to climate change. By 2070, two ecosystems lose about $4000(15 \%)$ and $7000(31 \%) \mathrm{km}^{2}$ of suitable climate area within their current boundaries (the Western Great Plains Sandhill Steppe and SonoraMojave Creosotebush-White Bursage Desert Scrub ecosystems, respectively). The climatic areas of riparian ecosystems are expected to be reduced by half.

Conclusions Results provide specific climate and vegetation parameters for anticipating how, where and when ecosystem vegetation transforms with climate change. Projecting the loss of suitable climate for the vegetation composition of ecosystems is important for assessing ecosystem threats from climate change and for setting priorities for ecosystem conservation and restoration across the southwestern USA.

Keywords Terrestrial ecosystems - Climate change · Vegetation composition - Large area landscapes . Southwest USA · Bioclimate 


\section{Introduction}

Typically, scientific applications relying on climate change projections focus on average temperatures (Hare and Meinshausen 2006). While averages help with understanding generalized climatic changes, they tell little about how, where and when ecosystem properties, such as the composition of vegetation, respond to climate change. Some predictions of biotic responses to climate rely on envelope models (Pearson and Dawson 2003). While substantial work and debate focuses on bioclimate envelope modeling to predict species distributions (Busby 1991; Pearson and Dawson 2003; Elith and Leathwick 2009; Dainese 2012), few studies explore the issue of compositional responses of ecosystems to climate change, particularly at the floristic level (Baselga and Araújo 2009; Pucko et al. 2011; Friggens et al. 2012). Halpin (1997) showed that when the envelope of climatic conditions describing the distribution of an ecosystem no longer exists at a location, the ecosystem contracts and eventually disappears. Until a clear systematic basis for providing such information is developed, landscape scale ecosystems will remain rather amorphous entities: challenging to define, threats upon them hard to assess, and their ecological planning relegated to simply acknowledging that changes will happen. Without appropriate information, it will be difficult to predict specific landscape level outcomes or prepare adaptive management responses.

We address these issues by identifying relationships between the vegetation composition of ecosystems and bioclimatic variables. Our methods and results predict: (a) which ecosystems are most sensitive to changes of climate at the level of community composition, (b) the compositional direction of changes in vegetation that is likely to result, (c) the potential amount of area affected, and (d) potential magnitude of change. We focus on 39 ecosystems within the Southwest region of the USA (Fig. 1). Bioclimate is that set of climate variables which best explain the distribution of a given species or community, to the extent that climate influences its occurrence and make-up per se (Table 1). Our methods identify which bioclimatic variables best explain vegetation composition at local scales $\left(\sim 1 \mathrm{~km}^{2}\right)$. This process characterizes the principal vegetation related climatic properties of defined ecosystem types.
Subsequently, changes in vegetation composition along the primary bioclimate gradients of the ecosystems are quantified. We show the spatial expression of these gradients in relation to ecosystem occurrence. These relationships are then coupled with climate projections for the 2030s, 2050s and 2070s (Ramirez and Jarvis 2008; Donner et al. 2011), revealing the location, type and pace of projected ecosystem change. Effects of climate change are also assessed by measuring the area of suitable climate remaining within the boundaries of contemporary ecosystems under future climate projections. The procedure describes how the patterns of future climate across an ecosystem's current area are expected to differ from that which is suitable for its current composition. It offers more than a simple boundary shift model, as changes may occur anywhere within an ecosystem. This is important because, for instance, landscape fragmentation metrics can then be derived, yielding a more thorough understanding of how climate change is likely to alter spatial patterns of habitat at the patch scale of land management.

\section{Methods}

Our approach relies on observed relationships between the plant species composition of defined ecosystems and climate variables (Fig. 2).

We began by identifying the minimum least correlated set of bioclimatic variables that best explain the plant species composition of each ecosystem. Beta turnover (Tuomisto 2010) of the cline occurring across the bioclimate gradients of these ecosystems was quantified in order to measure the relationship between bioclimate and the composition of plant species across these ecosystems (Whittaker 1967). Then we identified places on the landscape where the bioclimate gradient is steep or gradual, indicating where the magnitude of climate forcing on these ecosystems is stronger or weaker across the landscape, given the continuous variation of bioclimate values over space and time. Lastly, within the boundaries of the ecosystems having the strongest compositionbioclimate relationships we calculated the amount of area projected into the 2030s, 2050s, and 2070s that is expected to retain the same range of bioclimate values in the future as the contemporary normals. This approach enables us to describe the amount of each 


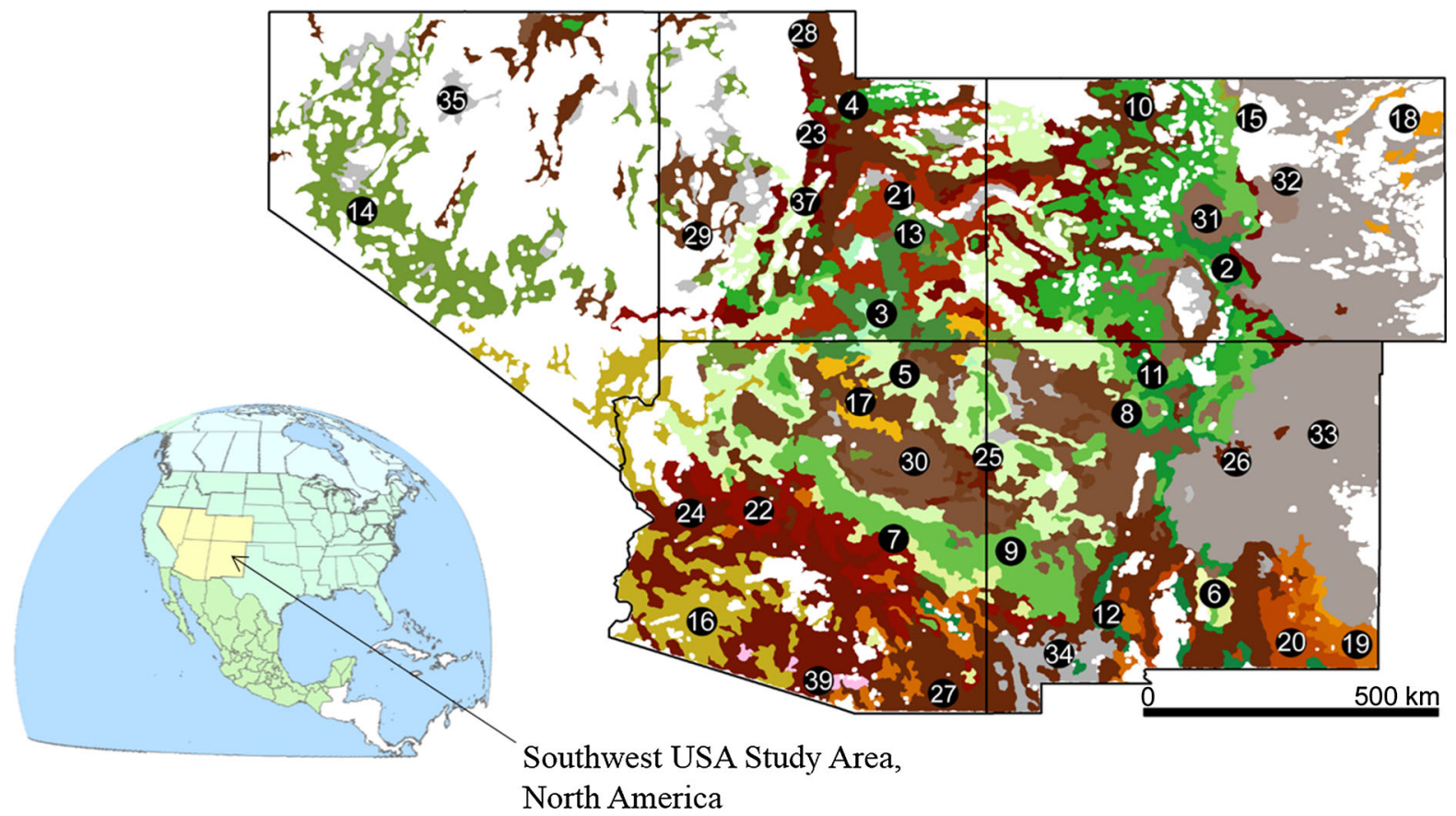

Fig. 1 Generalized distributions of the 39 ecosystems across the southwestern USA. Numbers indicate the following ecosystems, based on the U.S. National Vegetation Classification Group level names (Ecological Society of America et al. 2015). 1 Rocky Mountain Cliff, Canyon and Massive Bedrock; 2 Inter-Mountain Basins Active and Stabilized Dune; 3 Colorado Plateau Mixed Bedrock Canyon and Tableland; 4 Rocky Mountain Aspen Forest and Woodland; 5 Colorado Plateau Pinyon-Juniper Woodland; 6 Madrean Lower Montane PineOak Forest and Woodland; 7 Madrean Pinyon-Juniper Woodland; 8 Southern Rocky Mountain Dry-Mesic Montane Mixed Conifer Forest and Woodland; 9 Southern Rocky Mountain Ponderosa Pine Woodland; 10 Rocky Mountain Subalpine DryMesic Spruce-Fir Forest and Woodland; 11 Southern Rocky Mountain Pinyon-Juniper Woodland; 12 Chihuahuan Creosotebush Desert Scrub; 13 Colorado Plateau Blackbrush-Mormontea Shrubland; 14 Inter-Mountain Basins Mixed Salt Desert Scrub; 15 Rocky Mountain Lower Montane-Foothill Shrubland; 16 Sonora-Mojave Creosotebush-White Bursage Desert Scrub; 17 Southern Colorado Plateau Sand Shrubland; 18 Western Great Plains Sandhill Steppe; 19 Apacherian-Chihuahuan Mesquite Upland Scrub; 20 Chihuahuan Mixed Desert and

ecosystem's area where the climate is expected to change beyond its contemporary range of variation.

Study area

We examined 39 ecosystems spanning the southwestern USA (Fig. 1). Comer et al. (2003) described these ecosystems and the USGS Gap Analysis Program (Prior-Magee et al. 2007) as well as NatureServe
Thorn Scrub; 21 Colorado Plateau Pinyon-Juniper Shrubland; 22 Mogollon Chaparral; 23 Rocky Mountain Gambel OakMixed Montane Shrubland; 24 Sonoran Paloverde-Mixed Cacti Desert Scrub; 25 Inter-Mountain Basins Juniper Savanna; 26 Southern Rocky Mountain Juniper Woodland and Savanna; 27 Apacherian-Chihuahuan Semi-Desert Grassland and Steppe; 28 Inter-Mountain Basins Montane Sagebrush Steppe; 29 InterMountain Basins Semi-Desert Shrub-Steppe; 30 Inter-Mountain Basins Semi-Desert Grassland; 31 Southern Rocky Mountain Montane-Subalpine Grassland; 32 Western Great Plains Foothill and Piedmont Grassland; 33 Western Great Plains Shortgrass Prairie; 34 Chihuahuan Loamy Plains Desert Grassland; 35 Inter-Mountain Basins Greasewood Flat; 36 North American Warm Desert Wash; 37 Rocky Mountain Lower Montane-Foothill Riparian Woodland and Shrubland; 38 North American Warm Desert Lower Montane Riparian Woodland and Shrubland; 39 North American Warm Desert Riparian Woodland and Shrubland. Ecosystem numbers 1, 36, and 38 are absent from the map, given the coarse map scale and resolution. Geographic data of ecosystems are from NatureServe (2009)

(2009) mapped them. The ecosystems correspond to the "Group" level classification of vegetation types defined in the U.S. National Vegetation Classification (Ecological Society of America et al. 2015). Together the 39 ecosystems cover an area of $1,228,167 \mathrm{~km}^{2}$. The largest ecosystem is the Western Great Plains Shortgrass Prairie $\left(157,330 \mathrm{~km}^{2}\right)$, and the smallest is the North American Warm Desert Lower Montane Riparian Woodland and Shrubland $\left(2262 \mathrm{~km}^{2}\right)$. We 
Table 1 Bioclimatic variables and their explanation. Based on Hijmans and others (2005) with the exception of vapor pressure deficit, which is based on Lowry and Lowry (1989) and Snyder and Paw (2002)

\begin{tabular}{|c|c|}
\hline Bioclimatic variable & Explanation \\
\hline Mean annual temperature & The mean of all the monthly mean temperatures \\
\hline Mean diel temperature range & The mean of monthly diel temperature ranges \\
\hline Isothermality & The mean diel range divided by the annual temperature range $(\times 100)$ \\
\hline Temperature seasonality & $\begin{array}{l}\text { The standard deviation of monthly mean temperatures expressed as a percentage of the annual } \\
\text { mean }(\times 100)\end{array}$ \\
\hline $\begin{array}{l}\text { Maximum temperature of warmest } \\
\text { month }\end{array}$ & The highest temperature of any monthly maximum temperature \\
\hline $\begin{array}{l}\text { Minimum temperature of coldest } \\
\text { month }\end{array}$ & The lowest temperature of any monthly minimum temperature \\
\hline Temperature annual range & Maximum temperature of warmest month-minimum temperature of coldest month \\
\hline Mean temperature of wettest quarter & The mean temperature of wettest quarter ${ }^{\mathrm{a}}$ of the year ${ }^{\mathrm{b}}$ \\
\hline Mean temperature of driest quarter & The mean temperature of the driest quarter of the year \\
\hline $\begin{array}{l}\text { Mean temperature of warmest } \\
\text { quarter }\end{array}$ & The mean temperature of the warmest quarter of the year \\
\hline Mean temperature of coldest quarter & The mean temperature of the coldest quarter of the year \\
\hline Annual precipitation & The sum of monthly precipitation across the year \\
\hline Precipitation of wettest month & The total precipitation of the wettest month \\
\hline Precipitation of driest month & The total precipitation of the driest month \\
\hline Precipitation seasonality & The standard deviation of monthly precipitation expressed as a percentage of the annual mean \\
\hline Precipitation of wettest quarter & The total precipitation of the wettest quarter of the year \\
\hline Precipitation of driest quarter & The total precipitation of the driest quarter of the year \\
\hline Precipitation of warmest quarter & The total precipitation of the warmest quarter of the year \\
\hline Precipitation of coldest quarter & The total precipitation of the coldest quarter of the year \\
\hline $\begin{array}{l}\text { Vapor pressure deficit, average } \\
\text { annual }\end{array}$ & The difference between average annual saturation vapor pressure and actual vapor pressure \\
\hline
\end{tabular}

selected this study area because of its sensitivity to habitat alterations from climate change (Seager et al. 2007).

Data types, sources, and preparation

Data used in this study consisted of field plot observations of plant species composition, bioclimatic variables and mapped ecosystem distributions. For the field plots, we used data generated by the USGS National Gap Analysis Program (Prior-Magee et al. 2007) gathered between 2000 and 2003. These data consist of plant species names, percent cover by species, date of observation, geographic coordinates, and ecosystem type in $10 \times 10$ or $20 \times 20 \mathrm{~m}$ field plots. We standardized the plant species names to a single synonym using the USDA PLANTS database (USDA Natural Resources Conservation Service 2010) at the species level (subspecies and varieties were dropped).

Spatial data for 19 of the 20 bioclimatic variables was provided by Hijmans and others (2005). These data represent average (i.e., normal) climate conditions between 1950 and 2000. The data occur at a 30 arc-second horizontal cell size at the ground surface, or about $1 \mathrm{~km}^{2}$ at a spheroid projection. We also included vapor pressure deficit (VPD) as a bioclimatic variable since an elevated VPD increases evapotranspiration, raising environmental aridity and plant desiccation (Lowry and Lowry 1989). Vapor pressure 


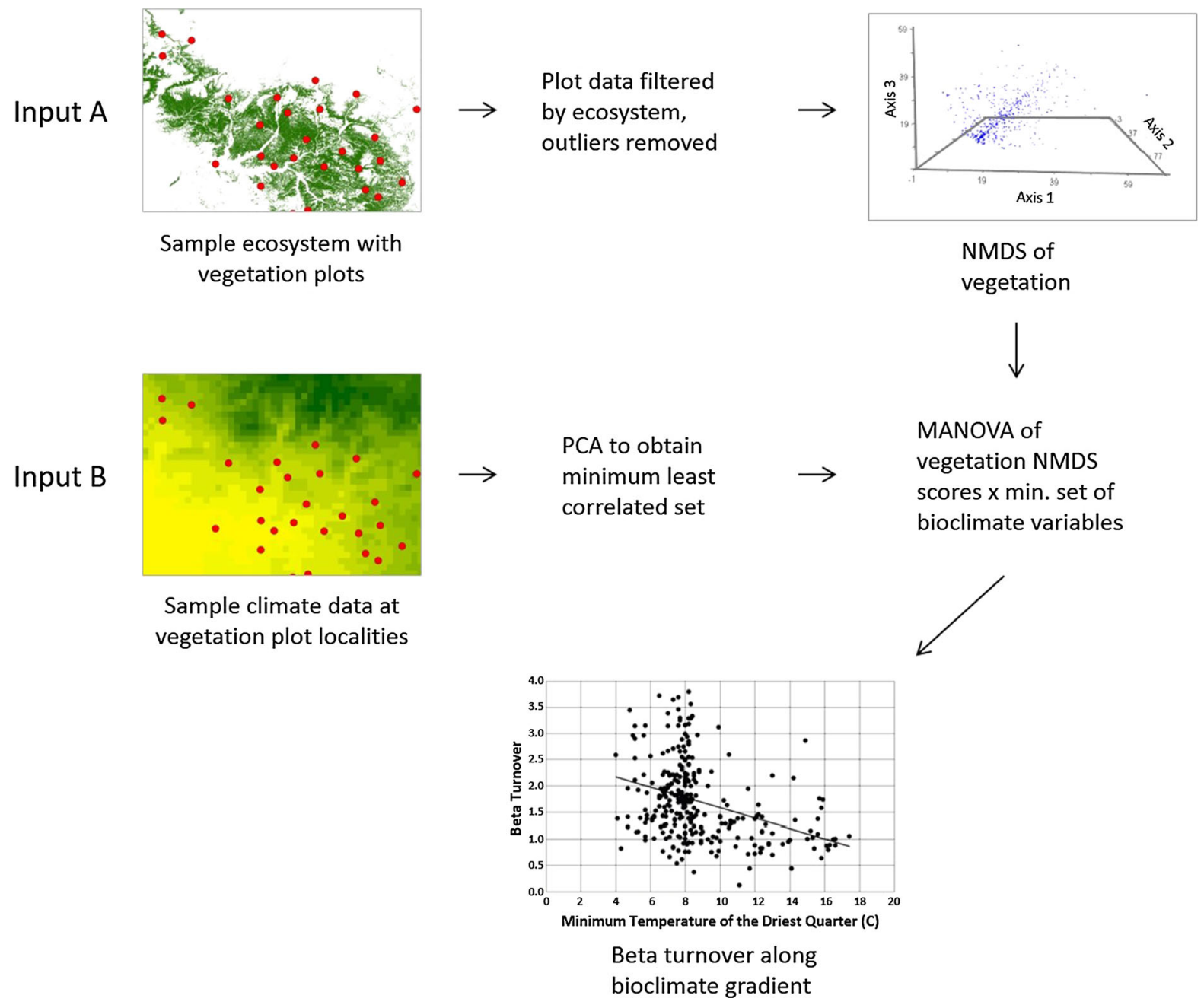

Fig. 2 Analytical process steps. Input A shows the steps used to derive the dependent variables (vegetation species composition) while Input $B$ shows the steps used to develop the independent variables (bioclimate)

deficit was calculated according to the methods of Snyder and Paw (2002) from data provided by Thornton et al. (2012) spanning 1980-2003. These data occur at a $1 \mathrm{~km}^{2}$ horizontal cell size at the ground surface.

We relied on GIS data from Prior-Magee et al. (2007) and NatureServe (2009) for geographical occurrences of the 39 ecosystems. These data have a $30 \mathrm{~m}$ horizontal ground resolution. Climate variables at each field plot location were extracted from gridded bioclimate datasets of Hijmans et al. (2005) as well as the VPD data derived from Thornton et al. (2012).

In the evaluation of the future amount of ecosystem area projected to retain the same range of bioclimate values as the contemporary climate, projected climate data for the 2030s, 2050s, and 2070s were derived from the GDFL CM3 model (Donner et al. 2011) RCP 8.5 (Moss et al. 2010) downscaled to a 30 arc-second horizontal resolution (Ramirez and Jarvis 2008).

Treatment of vegetation field plot data

The field plot records were stratified by ecosystem and overlaid onto the ecosystem maps. Plots falling outside the boundary of a mapped ecosystem that they had been assigned to during field collection were removed from the analysis. Plots having out-of-range species cover values $(>100 \%$ or $<1 \%)$ were also removed. For each ecosystem, a matrix of the percent cover for each species in each plot was assembled. A 
multivariate outlier analysis was performed on these matrices by calculating a Sørenson distance measure of species and their relative abundance (as percent cover) by plot (McCune et al. 2002). Plot records with $>2$ standard deviations from the mean distance were excluded. Out of an initial 30,380 field plots, $18,533(61 \%)$ were ultimately used. The number of usable plots per ecosystem ranged from 22 to $>2000$, with a mean of 475 per ecosystem.

To quantify vegetation composition, the remaining field plot records of each ecosystem were input into a nonmetric multidimensional scaling (NMDS) ordination (Kruskal 1964) using a Sørenson distance measure, a random starting configuration, and a Monte Carlo test. Stress values obtained from the actual data and the Monte Carlo test were compared to evaluate the stability of the final solution. The orthogonality among the output axes was compared to establish the extent to which each represents an independent index of the compositional similarity in species identity and population abundance among the field plots (Appendix 1 in supplementary material).

The NMDS procedure locates each field plot in multidimensional species space, given its coordinate value along each of the axes. Among the axes, the coordinate values indicate the distance and direction of vegetation composition in one field plot relative to all other field plots (McCune et al. 2002). We used the field plot values from three axes as the dependent variables for evaluating the relationships between vegetation composition and the bioclimatic variables within each ecosystem.

\section{Treatment of bioclimate data}

Bioclimate values were extracted at each field plot location. Within each ecosystem, values of the 20 bioclimatic variables (Table 1) from the field plot localities were examined for skewness and found to be within normally distributed bounds, though peakedness was evident in some cases. Pearson's correlation coefficients (Pearson 1896) were calculated for each pair of values for the 20 bioclimatic variables per ecosystem. Many of the variables were correlated to some extent. Therefore, we identified a minimum, least correlated set of climate variables that captured $\sim 90 \%$ of the overall climate information present among the field plot localities within each ecosystem. To do this, a principal components procedure (Mardia et al. 1979) was used to reduce the climatic variables to sets of "principal components" ranked by the amount of information retained in each set. Within each principal component, "loading" values describe the relative importance of each variable with respect to the total amount of information represented by each component. Through a process of elimination, variables were identified in each of the highest-ranking components which had both the highest loading values and which were the least correlated with the other variables (that is, the least correlated highest-ranking variables within the top components that explain $>90 \%$ of variability). This procedure resulted in a minimum least correlated set of independent, explanatory variables (often four to eight).

\section{Analysis of variance}

Each ecosystem was modeled separately. A multivariate analysis of variance (MANOVA) (Grimm and Yarnold 1995) was used to quantify relationships between the NMDS compositional indices of the vegetation plot data and the minimum least correlated set of bioclimatic variables. Bioclimatic variables with a resulting $p$ value $>0.05$ were rejected. The remaining variables were ranked according to the multivariate Wilks' lambda $(\lambda)$ and the approximate F-statistic (Bray and Maxwell 1985). Wilks lambda values were transformed to $1-\lambda$ to indicate the amount of compositional variability explained. The bioclimatic variables with the most explanatory power were those having the highest $1-\lambda$ in combination with a significant break in the sequence of approximate F-statistic values. In those cases where multiple variables qualified under this procedure, we examined pairwise correlation values between the variables. For those variables with correlations $>0.5$, the variable having the higher $1-\lambda$ value was selected. Where more than one bioclimatic variable was identified and correlations were $<0.5$, the set was retained.

Beta turnover across bioclimate gradients

An informative way to characterize biotic response(s) to an environmental gradient is by the pattern of species turnover along the gradient. This turnover is one form of beta diversity (Whittaker 1972) or beta turnover (Tuomisto 2010). In this application, we expected the change of vegetation along the identified bioclimate gradient to reveal a compositional 
response to the bioclimatic variable(s). This approach links the magnitude and direction of the compositional changes in vegetation to the corresponding bioclimatic variables, whether the gradients occur across geographical space or time.

The amount of beta turnover was derived using the methods of Oksanen and Tonteri (1995). The fit of beta turnover to bioclimatic variable(s) was described using ordinary least squares regression (Anderson 2008), resulting in the descriptive statistics of: the mean and range of y (beta turnover) values, slope of the fitted line, $y$ intercept, range of $y$ values along the slope, and relative slope. Relative slope is $\mathrm{y}_{\mathrm{s}} /$ $y_{r} \times 100$, where $y_{s}$ is the range of $y$ values along the fitted slope and $y_{r}$ is the total range of $y$ values (Appendix 2 in supplementary material). Relative slope was calculated for comparative purposes since the bioclimatic variable units are heterogeneous (e.g., precipitation in $\mathrm{mm}$, temperature in degrees $\mathrm{C}$, and indices such as isothermality) so that the absolute slope values by themselves are not comparable across bioclimate types. The magnitude of the relative slope response in each ecosystem was categorized as strong, moderate, or weak by applying Jenks (1967) breaks to the relative slope vector (Table 2).

\section{Assumptions and limitations}

These methods assume that the vegetation composition of the ecosystems respond to particular climate variables, and that these 20 bioclimatic variables adequately explain most of the vegetation composition response to climate in general. Additionally, it is assumed that the relatively large numbers of field observations per ecosystem adequately represent the vegetation heterogeneity of the ecosystems studied. Furthermore, we accepted that: (a) The NMDS procedure adequately represents the multidimensional similarity between any given field plot and all other field plots within a given ecosystem. (b) The PCA procedure robustly identifies the minimum least correlated set of bioclimatic variables that explain about $90 \%$ of the climate information contained in the set of 20 bioclimatic variables. (c) The MANOVA test identifies the minimum set of bioclimatic variables which explain most of the vegetation composition that can be explained by climate; and (d) the method for quantifying a beta turnover gradient is robust.

Limitations to our approach include: (a) Other biophysical processes may also exert control over the composition of the vegetation, making discovery of the climate signal difficult or impossible. (b) Interaction among and rates of change in bioclimatic variables shaping an ecosystem's vegetation composition may consist of more fine grained complexity than our methods are capable of capturing. (c) The methods used here apply to the range of variation within a given ecosystem and do not address invasions of exotic species or altered disturbance regimes.

\section{Results}

The vegetation composition in each of the 39 ecosystems responds to distinct bioclimatic variables (Appendix 3 in supplementary material), though the magnitude of response varies. Four of the 20 climate variables explain most of the variability in vegetation composition among the ecosystems. These are: (a) the seasonality of precipitation, (b) the seasonality of temperature, (c) mean annual precipitation and (d) the amount of precipitation during the warmest quarter. These variables form the primary climatic predictors of vegetation composition in 16 ecosystems and contribute to the predictions in 6 others. They explain most of the climate related vegetation composition

Table 2 Number and percent of ecosystems responding to bioclimatic variables by relative slope category. Category thresholds are per Jenks (1967) natural breaks

\begin{tabular}{lccc}
\hline Beta response category & Number of ecosystems & Percent of ecosystems (\%) & Relative slope thresholds \\
\hline Strong & 12 & 31 & $>40$ \\
Moderate & 9 & 23 & $27-40$ \\
Weak & 15 & 38 & $<27$ \\
Mixed & 3 & 8 & \\
\hline
\end{tabular}




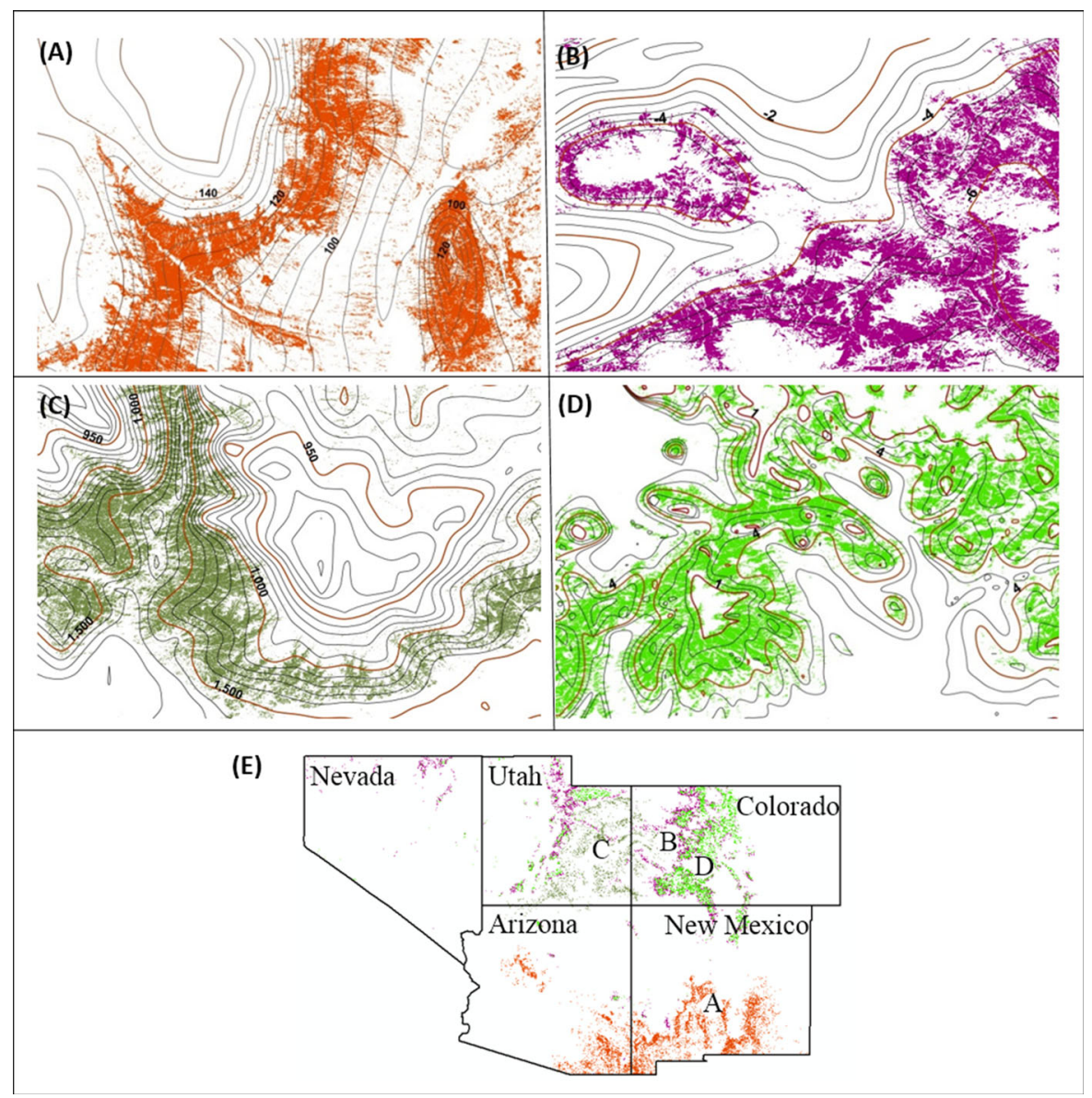

Fig. 3 Landscape scale bioclimate gradients: a Contours of precipitation of the wettest month in relation to the ApacherianChihuahuan Semi-Desert Grassland and Steppe ecosystem, in orange. Contours interval is $4 \mathrm{~mm}$ precipitation, scale is 1:250,000. b Contours of minimum temperatures of the coldest month in relation to the Rocky Mountain Aspen Forest and Woodland ecosystem, in purple. Contours interval is $1{ }^{\circ} \mathrm{C}$, scale is $1: 250,000$. c Contours of precipitation seasonality in relation to the Colorado Plateau Pinyon-Juniper Shrubland ecosystem, in

across $752,030 \mathrm{~km}^{2}(61 \%)$ of natural vegetation land cover across the Southwest study area.

Among the 39 ecosystems, beta turnover varied by $95 \%$. This variability is likely due to the climate niche widths of the prevalent species and the influence of other biophysical factors, such as disturbance, competition, herbivory, and soils. Bioclimate related beta turnover was normalized among the different ecosystems for comparative purposes. A steeper response slope indicates a stronger bioclimate-composition relationship in one ecosystem relative to another. The composition of 12 ecosystems have relatively dark green. Contours interval is 10 seasonality index points (see definition, Table 1), scale is 1:350,000. d Contours of mean temperature of driest quarter in relation to the Rocky Mountain Subalpine Dry-Mesic Spruce-Fir Forest and Woodland ecosystem, in light green. Contours are at intervals of $1{ }^{\circ} \mathrm{C}$, scale is 1:300,000. e Locations of panels (a-d). Contours derived from data of Hijmans et al. (2005); ecosystem distributions derived from data of NatureServe (2009)

strong responses to climate, 9 have moderate responses, and 15 significant but relatively weak responses. Three ecosystems showed mixed responses (Table 2).

The Sonora-Mojave Creosotebush-White Bursage Desert Scrub ecosystem had the steepest relative slope (94; Appendix 2 in supplementary material), where beta turnover increased with temperature seasonality. The Rocky Mountain Cliff, Canyon and Massive Bedrock ecosystem and the Rocky Mountain Lower Montane-Foothill Riparian Woodland and Shrubland ecosystem also had steep relative slopes (73 and 66; 
Appendix 2 in supplementary material). These ecosystems have strong relationships with precipitation during the driest and coldest quarters, respectively. For both, beta turnover declines with increasing precipitation. Since these three ecosystems have large beta turnover, they hold a high potential for changes in vegetation composition across geographical space relative to changes in the bioclimatic variables predicting them.

The geographical areas within ecosystems where the bioclimate gradients are steeper are more likely to experience greater changes in vegetation composition over space and time. To identify and describe places where such gradients occur, spatial contours of the explanatory bioclimatic variables were overlaid onto maps of the ecosystem's distributions. Ecosystems having a strong to moderate relationship with bioclimate show considerable spatial correspondence between the ecosystems' landscape configuration and bioclimate contours (Fig. 3).

With the composition-bioclimate approach, floristically based climatic boundaries of ecosystems can be identified, which better resolves ecosystem types. For example, vegetation of the Southern Rocky Mountain Dry-Mesic Montane Mixed Conifer Forest and Woodland ecosystem is best explained by the minimum temperatures during the driest quarter. Yet this relationship is not uniform. One area of this ecosystem has a relative beta diversity response slope 3.6 times greater than the other, whereby beta turnover increases as temperature drops (Appendix 4 in supplementary material). Although mapped and described as a single ecosystem (NatureServe 2009), the methods used here capture a distinct separation (see Sesnie et al. 2012).

We linked 11 southwestern ecosystems having strong bioclimatic relationships with downscaled projections of future climates (Ramirez and Jarvis 2008; Donner et al. 2011). This step illustrates how a better understanding of the relationships between bioclimate and ecosystem vegetation composition can address applied problems. The resulting estimates describe how ecosystem vegetation might change in future decades (2030s, 2050s, 2070s), given reconfigurations of the bioclimate variables required by an ecosystem's current vegetation. In doing so, these results identify where changes in ecosystem vegetation may occur and their pace (Appendix 5 in supplementary material).
Projections of future climates indicate that 7 of the 12 ecosystems with strong bioclimatic responses are expected to experience large changes to their area of suitable climate (Appendix 5 in supplementary material). For example, by the 2070 s, the Sonora-Mojave Creosotebush-White Bursage Desert Scrub ecosystem is forecast to lose $\sim 15 \%$ of its bioclimatic area. The extent of this ecosystem is large $\left(46,000 \mathrm{~km}^{2}\right)$ and the percent of loss equates to $\sim 7000 \mathrm{~km}^{2}$, roughly the size of the U.S. state of Connecticut. The Western Great Plains Sandhill Steppe is also relatively large and the amount of bioclimate area lost $(31 \%)$ equates to $\sim 4000 \mathrm{~km}^{2}$ - an area 1.3 times the size of Rhode Island.

The North American Warm Desert Lower Montane Riparian Woodland and Shrubland ecosystem is relatively small $\left(\sim 2000 \mathrm{~km}^{2}\right)$. However, by the 2070s, half of its bioclimatic area is projected to consist of a different climate, and likely a different ecosystem type (Appendix 5 in supplementary material). Importantly, riparian ecosystems are keystone habitats, hubs of biological diversity and essential for sustaining life processes in arid landscapes (Chambers and Miller 2004). Given the amounts of change in vegetation composition that is possible over a short period ( $\sim 50$ years), the consequences for biodiversity and its stewardship in riparian along with surrounding ecosystems could be substantial.

Results also show how alterations to an ecosystems' vegetation composition can occur internally, even when the climatic conditions that best explain its composition remain within the overall range of contemporary values but change geographically. For example, the Madrean Pinyon-Juniper Woodland ecosystem has a strong relationship with precipitation seasonality (relative slope $=42$; Appendix 2 in supplementary material). Presently, the distribution of values for precipitation seasonality span 43-132 units. By the $2030 \mathrm{~s}$ the overall range of these values is reduced by one-half, yet this reduced range of values still occupies the contemporary geographic distribution of the ecosystem (Fig. 4). Although the total ecosystem area is expected to remain unchanged through the 2070s, the range of climatic variability across this $18,927 \mathrm{~km}^{2}$ landscape narrows markedly. Its vegetation composition is expected to become more uniform. The implications for this ecosystem, whether increased vulnerability to disturbances, a 
reduction in habitats for vertebrates, or altered provisioning of ecosystems services, remain unknown.

\section{Discussion}

Although other biophysical dynamics influence species composition to a greater or lesser degree, the approach taken in this study isolates the influence of climate on vegetation composition. The stepwise process enables testing, calibration, and evaluation throughout each interval of the modeling sequence.

Our methods revealed a striking relationship between the Madrean Pinyon-Juniper Woodland ecosystem and precipitation seasonality (i.e. the range of variability in the seasonality of precipitation). This relationship demonstrates three facets of ecosystem change (Fig. 4). Namely: (a) The magnitude of the change in the variability of the seasonality metric itself; (b) That the change is not uniform across the ecosystem's geographic occurrence. Instead, the change exhibits a strong spatial dependency. (c) The change in the variability of this ecosystem's primary bioclimatic variable occurs within the ecosystem's current climate space. Hence, the spatial distribution of the ecosystem's overall climate envelope remains unchanged, yet internally the variability of seasonal precipitation changes dramatically. In aggregate, this example shows how changes in an ecosystem's suitable climate can be more nuanced than simple shifts in presence-absence. We anticipate that further analyses will reveal other critical but complex

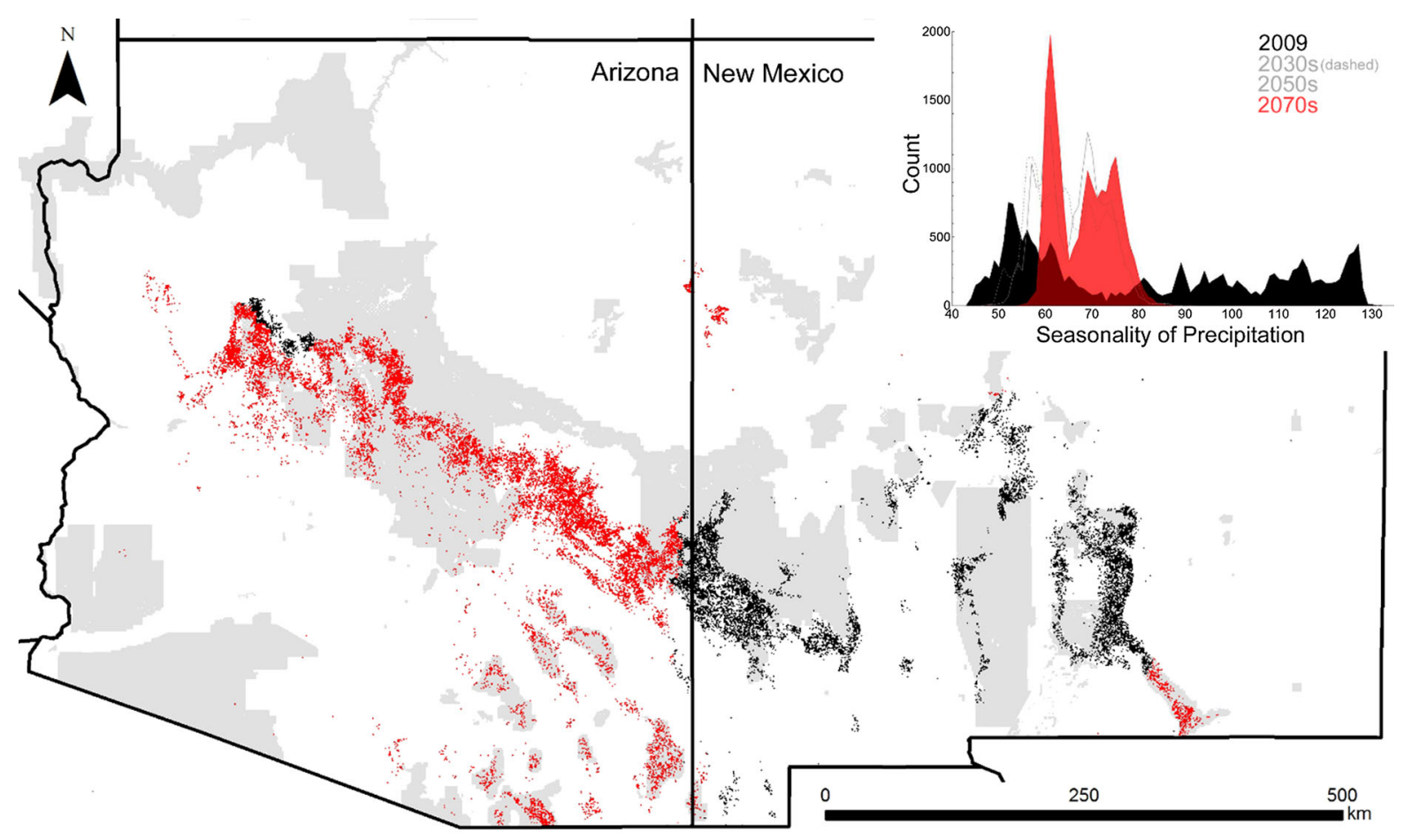

Fig. 4 Geographical distribution of the Madrean PinyonJuniper Woodland in the southwestern United States (states of Arizona and New Mexico). This ecosystem has a strong relationship with the seasonality of precipitation (i.e. annual variability of precipitation; Appendix 2 in supplementary material). The location of red and black pixels illustrate the geographical distribution of this ecosystem's bioclimate, which remains unchanged from 2009 to 2070s. Red pixels identify seasonality of precipitation values of 47-91, while black indicates all other values. In 2009, pixel values range from 43 to 132 , as depicted in the figure (red and black pixels, depending on their value). By the 2070s, the range of seasonality of precipitation values are halved to 47-91 (red colored pixels), mainly from a contraction in the higher values. Therefore, all of the pixels in the figure are predicted to remain this ecosystem type in the 2070s (but given their values, they would be colored red in the figure). The effects of reduced precipitation variability across this ecosystem's geographical space, regarding its resilience to disturbance or other dynamics is unknown. Gray polygons identify property administered by the U.S. Department of Defense, U.S. Fish and Wildlife Service, U.S. Forest Service and the National Park Service. Count represents pixels of $1 \mathrm{~km}^{2}$ 
expressions of altered bioclimates. Such knowledge should lead to a far greater understanding of how climate change influences large ecosystems. Societal responses to climate induced changes in ecosystem services could become more successful as a result.

The Madrean Pinyon-Juniper Woodland ecosystem exhibited a large change in precipitation seasonality between the reference period and the 2030s, as well as between the 2030s and the 2070s. As above, these changes are strongly geographic. They correspond to land form in combination with their position relative to the Gulf of Mexico. We speculate that this spatial change in the variability of precipitation seasonality is related to future changes in the monsoonal dynamics of the region.

To exemplify the application of our methods to future climates, we relied on the RCP 8.5 climate scenario from the GFDL CM3 model. Our rationale for using a single model, and the GFDL CM3 in particular, is that of the many factors to consider when deciding on appropriate climate data inputs for modeling, one must first identify the object of interest. In this case, the object is biotic responses to climate (as opposed to, for example, the response of ocean circulation or cryosphere dynamics to climate). Biota do not respond to climate per se, but to particular climatic conditions that limit or facilitate their establishment or persistence (i.e. bioclimatic variables). Therefore, it is critical that the climate data used expresses such limitation or facilitation thresholds well. However, these characteristics often occur as extremes located in the tails of the distribution. While ensemble data serve a useful purpose in expressing the central tendency among a suite of general circulation models, the signals that limit or facilitate biotic occurrence may be dampened or otherwise skewed (e.g., Vavrus et al. 2015) by an ensemble's rules of combination. As discussed by Tebaldi and Knutti (2007), the reliance on consensus estimates via ensembles carry inherent challenges, including (a) the choice of metrics and diagnostics of performance, (b) inter-model dependencies and common biases, (c) compounding of errors, and (d) the representativeness of the sample of models with regard to common fundamental uncertainties. This is not to say that the central tendency in the suite of models is unimportant. Instead, our point is that because of these issues, we chose a single, well-vetted model performing close to the ensemble central tendency to derive future projections of bioclimatic variables. A full analysis describing projections of future vegetation composition via multiple climatic scenarios is beyond the scope of this paper. This topic is, however, being addressed in ongoing work.

By swapping space for time (Ferrier and Guisan 2006; Elith and Leathwick 2009) along the climatecomposition gradient, a first order explanation of how vegetation composition is likely to change in response to incremental changes in primary climate variables is possible. Blois et al. (2013), caution that at time scales of years or spatial resolutions of kilometers or less, stochastic processes could limit the utility of space-for-time substitution. However, the landscapes in this study cover areas of hundreds to many thousands of square kilometers, and are currently experiencing extraordinarily rapid climate change. Therefore, we expect this approach to be useful for anticipating changes of habitat composition over time across large landscapes and at the resolution of conservation and management areas. The methods in this study can also provide a reference framework for addressing the quandary over managing for the historical compliment of species in an area versus a changing composition of species and the direction such changes may take.

Our methods are applicable to a wide range of other problems. For example, recently the technical criteria for assessing threats to the persistence of ecosystems under the IUCN's Red List of Ecosystems (RLE) (Rodriguez et al. 2011; Keith et al. 2013) was questioned for its adequacy in the face of climate change (Boitani et al. 2015). Boitani et al. (2015) argue that the current RLE approach is inadequate because it lacks criteria for determining where along the compositional continuum of space and time an ecosystem ceases to exist. The methods for quantifying the relationships between ecosystem composition and gradients of environmental forcings provide the criteria for improving the RLE by delineating the bioclimatic boundaries of terrestrial ecosystems. Additionally, these methods provide a mechanism for quantifying the sensitivity of vegetation composition to the magnitude and rate of climate change, thereby aiding ecosystem threat assessment. 


\section{Conclusion}

Results from this study reveal several dimensions of how climate change influences the composition of terrestrial ecosystems. The methods provide the specific climate and vegetation parameters required for anticipating how, where and when ecosystem vegetation transforms with climate change. This information enables a ranking of ecosystems by their sensitivity to altered climates, thereby increasing the efficacy of resilience planning. Assessing ecosystem threats and predicting the future vegetation composition of ecosystems grows ever more important given the amount of climatic flux the planet is experiencing and the rates of changes expected (IPCC 2014).

Acknowledgments Thanks to Chris Cogan, Karen Humes, and Stuart Pimm for their reviews and support. Thanks also to Pat Comer and Jon Hak who were helpful with early ideas about the study. This project was supported by the U.S. Fish and Wildlife Service under Cooperative Agreement No. 20181AJ823 with the University of Idaho. The findings and conclusions are those of the authors and do not necessarily represent the views of the U.S. Fish and Wildlife Service or the U.S. Forest Service.

Open Access This article is distributed under the terms of the Creative Commons Attribution 4.0 International License (http:// creativecommons.org/licenses/by/4.0/), which permits unrestricted use, distribution, and reproduction in any medium, provided you give appropriate credit to the original author(s) and the source, provide a link to the Creative Commons license, and indicate if changes were made.

\section{References}

Anderson R (2008) Modern methods for robust regression. Sage Publications, Thousand Oaks

Baselga A, Araújo MB (2009) Individualistic versus community modelling of species distributions under climate change. Ecography 32(1):55-65

Blois JL, Williams JW, Fitzpatrick MC, Jackson ST, Ferrier S (2013) Space can substitute for time in predicting climatechange effects on biodiversity. Proc Natl Acad Sci 110(23):9374-937

Boitani L, Mace GM, Rondinini C (2015) Challenging the scientific foundations for an IUCN Red List of Ecosystems. Conserv Lett 8(2):125-131

Bray JH, Maxwell SE (1985) Multivariate analysis of variance. SAGE Publications, Newbury Park

Busby JR (1991) BIOCLIM: a bioclimate analysis and prediction system. In: Margules CR, Austin MP (eds) Nature conservation: cost effective biological surveys and data analysis. CSIRO, Canberra, pp 64-68
Chambers JC, Miller JR (eds) (2004) Great Basin riparian ecosystems: ecology, management, and restoration. Island Press, Washington, DC

Comer P, Faber-Langendoen D, Evans R, Gawler S, Josse C, Kittel G, Menard S, Pyne M, Reid M, Schulz K, Snow K, Teague J (2003) Ecological systems of the United States: a working classification of U.S. terrestrial systems. NatureServe, Arlington, p 75

Dainese M (2012) Using natural gradients to infer a potential response to climate change: an example on the reproductive performance of Dactylis glomerata L. Biology $1: 857-868$

Donner LJ, Wyman BL, Hemler RS, Horowitz LW, Ming Y, Zhao M, Golaz J-C, Ginoux P, LIN S-J, Schwarzkopf MD, Austin J, Alaka G, Cooke WF, Delworth TL, Freidenreich SM, Gordon CT, Griffies SM, Held IM, Hurlin WJ, Klein SA, Knutson TR, Langenhorst AR, Lee H-C, Lin Y, Magi BI, Malyshev SL, Milly PCD, Naik V, Nath MJ, Pincus R, Ploshay JJ, Ramaswamy V, Seman CJ, Shevliakova E, Sirutis JJ, Stern WF, Stouffer RJ, Wilson RJ, Winton M, Wittenberg AT, Zeng F (2011) The dynamical core, physical parameterizations, and basic simulation characteristics of the atmospheric component AM3 of the GFDL Global Coupled Model CM3. J Clim 24(13):3484-3519

Ecological Society of America, NatureServe, Federal Geographic Data Committee, U.S. Forest Service, U.S. Geological Survey (2015) The US National vegetation classification. Ecological Society of America, Washington, DC. http://www.usnvc.org

Elith J, Leathwick JR (2009) Species distribution models: ecological explanation and prediction across space and time. Annu Rev Ecol Evol Syst 40(1):677-697

Ferrier S, Guisan A (2006) Spatial modelling of biodiversity at the community level. J Appl Ecol 43(3):393-404

Friggens MM, Warwell MV, Chambers JC, Kitchen SG (2012) modeling and predicting vegetation response of western USA grasslands, shrublands, and deserts to climate change. In: Finch DM (ed) Climate change in grasslands, shrublands, and deserts of the interior American West: a review and needs assessment, general technical report, GTR-285, 285. U.S. Department of Agriculture, Forest Service, Rocky Mountain Research Station, Fort Collins, pp 1-21

Grimm LG, Yarnold PR (eds) (1995) Reading and understanding multivariate statistics. American Psychological Association, Washington, DC

Halpin PN (1997) Global climate change and natural-area protection: management responses and research directions. Ecol Appl 7:828-843

Hare B, Meinshausen M (2006) How much warming are we committed to and how much can be avoided? Clim Change 75(1):111-149

Hijmans RJ, Cameron S, Parra J (2005) WorldClim: global climate data. http://www.worldclim.org

IPCC (2014) Climate change 2014: synthesis report. In: Pachauri RK, Meyer L (eds) Intergovernmental panel on climate change. IPCC, Cambridge, p 138

Jenks GF (1967) The data model concept in statistical mapping. In: Frenzel K (ed) International yearbook of cartography. George Philip \& Son, London, pp 186-190

Keith DA, Rodríguez JP, Rodríguez-Clark KM, Nicholson E, Aapala K, Alonso A, Asmussen M, Bachman S, Basset A, 
Barrow EG, Benson JS, Bishop MJ, Bonifacio R, Brooks TM, Burgman MA, Comer P, Comín FA, Essl F, FaberLangendoen D, Fairweather PG, Holdaway RJ, Jennings M, Kingsford RT, Lester RE, Mac Nally R, McCarthy MA, Moat J, Oliveira-Miranda MA, Pisanu P, Poulin B, Regan TJ, Riecken U, Spalding MD, Zambrano-Martínez S (2013) Scientific foundations for an IUCN Red List of Ecosystems. PLoS One 8(5):e62111

Kruskal JB (1964) Nonmetric multidimensional scaling: a numerical method. Psychometrika 29(2):115-129

Lowry WP, Lowry PI (1989) Fundamentals of biometeorology, interactions of organisms and the atmosphere, vol I: the physical environment. Peavine Publications, McMinnville

Mardia KV, Kent JT, Bibby JM (1979) Multivariate analysis. Academic Press, London

McCune B, Grace JB, Urban DL (2002) Analysis of ecological communities. MjM Software Design, Gleneden Beach

Moss RH, Edmonds JA, Hibbard KA, Manning MR, Rose SK, van Vuuren DP, Carter TR, Emori S, Kainuma M, Kram T, Meehl GA, Mitchell JFB, Nakicenovic N, Riahi K, Smith SJ, Stouffer RJ, Thomson AM, Weyant JP, Wilbanks TJ (2010) The next generation of scenarios for climate change research and assessment. Nature 463(7282):747-756

NatureServe (2009) Terrestrial ecological systems of the United States. NatureServe, Arlington

Oksanen J, Tonteri T (1995) Rate of compositional turnover along gradients and total gradient length. J Veg Sci $6(6): 815-824$

Pearson K (1896) mathematical contributions to the theory of evolution. III. Regression, heredity, and panmixia. Philosophical Transactions of the Royal Society of London. Series A, containing papers of a mathematical or physical character 187 (Article type: research-article/Full publication date: 1896/Copyright (C) 1896 The Royal Society), pp 253-318

Pearson RG, Dawson TP (2003) Predicting the impacts of climate change on the distribution of species: are bioclimate envelope models useful? Glob Ecol Biogeogr 12(5):361-371

Prior-Magee JS, Boykin KG, Bradford DF, Kepner WG, Lowry JH, Schrupp DL, Thomas KA, Thompson BC (eds) (2007) Ecoregional gap analysis of the Southwestern United States. U.S. Geological Survey, Gap Analysis Program, Moscow, p 441

Pucko C, Beckage B, Perkins T, Keeton WS (2011) Species shifts in response to climate change: individual or shared responses? J Torrey Bot Soc 138(2):156-176
Ramirez J, Jarvis A (2008) High resolution statistically downscaled future climate surfaces. International Center for Tropical Agriculture, CGIAR Research Program on Climate Change, Agriculture and Food Security, Cali

Rodriguez JP, Rodriguez-Clark KM, Baillie JEM, Ash N, Benson J, Boucher T, Brown C, Burgess ND, Collen B, Jennings M, Keith DA, Nicholson E, Revenga C, Reyers B, Rouget M, Smith T, Spalding M, Taber A, Walpole M, Zager I, Zamin T (2011) Establishing IUCN Red List criteria for threatened ecosystems. Conserv Biol 25(1):21-29

Seager R, Ting M, Held I, Kushnir Y, Lu J, Vecchi G, Huang H-P, Harnik N, Leetmaa A, Lau N-C, Li C, Velez J, Naik N (2007) Model Projections of an imminent transition to a more arid climate in Southwestern North America. Science 316(5828):1181-1184

Sesnie SE, Dickson BG, Rundall JM, Sisk TD (ed) (2012) Assessment of mixed conifer forest conditions, North Kaibab Ranger District, Kaibab National Forest, Arizona, USA. Proceedings of the biennial conference of research on the Colorado Plateau. Colorado Plateau Research Station, Flagstaff, pp 23-42

Snyder RL, Paw KT (2002) Measuring vapor pressure deficit in the field. University of California, Davis

Tebaldi C, Knutti R (2007) The use of the multi-model ensemble in probabilistic climate projections. Philos Trans R Soc A Math Phys Eng Sci 365(1857):2053-2075

Thornton PE, Thornton MM, Mayer BW, Wilhelmi N, Wei Y, Cook RB (2012) Daymet: daily surface weather on a $1 \mathrm{~km}$ grid for North America, 1980-2011. Oak Ridge National Laboratory Distributed Active Archive Center, Oak Ridge

Tuomisto H (2010) A diversity of beta diversities: straightening up a concept gone awry. Part 1 . Defining beta diversity as a function of alpha and gamma diversity. Ecography 33(1):2-22

USDA Natural Resources Conservation Service (2010) The PLANTS database. National plant data team. Greensboro. Accessed 3 Dec 2012

Vavrus SJ, Notaro M, Lorenz DJ (2015) Interpreting climate model projections of extreme weather events. Weather Clim Extrem 10:10-28

Whittaker RH (1967) Gradient analysis of vegetation. Biol Rev 42(2):207-264

Whittaker RH (1972) Evolution and measurement of species diversity. Taxon 21:213-251 